\title{
Study of Efficiency and Environmental Performance of Propeller
}

\author{
Sulaiman Olanrewaju Oladokun* \\ School of Ocean Engineering, University Malaysia Terengganu, Malaysia
}

\begin{abstract}
The efficiency of propeller relation with the velocity of efflux plane, the distribution of axial velocity, the ratio of power required by the propeller and the power delivered to the propeller. This study investigated the current design of ship propeller to determine the efficiency impact on coastline. Propeller from RV Discovery is used in this study. The performance and the efficiency of the propeller were determined by using JavaProp software. The efficiency of the propeller is $50 \%$ which was good based on the propeller design. The environmental performances were determined by the range and speed of the distribution of axial velocity. The result has showed very good agreement with the previous research to validate the result.
\end{abstract}

Keywords: Propeller; Propeller jet; Ship induced wave; Seabed scouring; Shoreline erosion

\section{Introduction}

Propeller is a type of fan which is attached to the aft of ship and moves against resistant of water to drive the ship. It converts engine torque into propulsive force or thrust, thus overcoming ship's resistance to produce forward motion by creating a sternward accelerated column of water. In propeller design, it is important to ensure that it drives the vessel efficiently.

This study were focused on the propeller efficiency at optimum speed and impact of propeller wash to determine environmental performance of propeller in respect to impact such as coastal erosion seabed scouring, damage to moored vessel, marine structure and etc. $[1,2]$. This study is conducted base on theoretical modeling and simulation software [3]. Propeller efficiency is used to define how well a propeller transmits its rotational force or energy into thrust. The amount of energy it takes to rotate the propeller is almost always greater than the thrust from the propeller. Reducing the loss, and drag are the goal of propeller efficiency. The impact of a wave on a shoreline or structure is dependent on the parameters, wave height, wave period, wave direction and water depth. However, the common form of analysis is used for wind and waves are not directly applicable as there is so much variability in the parameters over the course of a single event. Stumbo et al. used an energy based analysis, whereby the total energy in the wave packet was determined and used as a design value [4,5]. Using this technique, he was able to assess the impact of different wave events on shorelines and structures.

The propeller affect the wake wash which cause coastal erosion and damage to the moored vessel, port, marine structure and marinas. Vessel movements in inland water require propulsive efficient and optimum speed [8]. Propeller jet caused seabed scouring [9]. This study determines the efficiency and environmental performance of propeller. This paper discusses the performance of current propeller design and the impact of propeller jet to environment.

\section{Methodology}

Tools employed in this study are described below:

JavaPropsoftware: JavaProp is software used in this study to analysis the propeller impact. This software can be used for both airplane and ship propeller because it's the analysis are not too details. As both propellers are used in different medium, this requires setting a few parameters to make sure there is good accuracy of the result. In this research the parameters which are needed to set up are density of water, kinematic viscosity of water and speed of sound in water.

Axial momentum theory: This theory is derived from the concept of conversation of momentum and energy, encompass five core assumptions:

i. The propeller is represented by an ideal actuator disc without thickness in the axial direction.

ii. The disc consists of an infinite number of rotating blades, covering the entire disc without space in between.

iii. The disc is submerged in an ideal fluid without disturbances.

iv. All elements of fluid passing through the disc undergo an equal increase of pressure.

v. The energy supplied to the disc is, in turn, supplied to the fluid without any rotational effects being induced [10] (Figure 1).

Efflux plane: Hamill et al. suggested the efflux velocity is influenced by other propeller characteristics such as blade area ratio and hub diameter of a propeller (Figure 2).

$$
\mathrm{V}_{0}=\mathrm{E}_{0} \mathrm{nD} \sqrt{\mathrm{C}_{\mathrm{t}}}
$$

Where, Hashmi HN (1993) proposed that the coefficient can be calculated using a semi-empirical equation by taking propeller diameter, hub diameter, thrust coefficient and blade area ratio into account.

$$
\mathrm{E}_{0}=\left(\frac{\mathrm{D}}{\mathrm{D}_{\mathrm{h}}}\right)^{-0.403} \mathrm{C}_{\mathrm{t}}^{-1.79} \mathrm{BAR}^{0.744}
$$

*Corresponding author: Prof. Madya Dr.Sulaiman Olanrewaju Oladokun, PhD CEng, CMarEng. School of Ocean Engineering, University Malaysia Terengganu, 21030, Malaysia, Tel: +609668-3697/ +60177244339/Fax: +609-6683193; E-mail: o.sulaiman@umt.edu.my, oosulaiman8@gmail.com

Received March 03, 2014; Accepted March 25, 2015; Published April 01, 2015

Citation: Oladokun SO (2015) Study of Efficiency and Environmental Performance of Propeller. J Coast Zone Manag 18: 400. doi: 10.4172/2473-3350.1000400

Copyright: ( $) 2015$ Oladokun SO, et al. This is an open-access article distributed under the terms of the Creative Commons Attribution License, which permits unrestricted use, distribution, and reproduction in any medium, provided the original author and source are credited. 


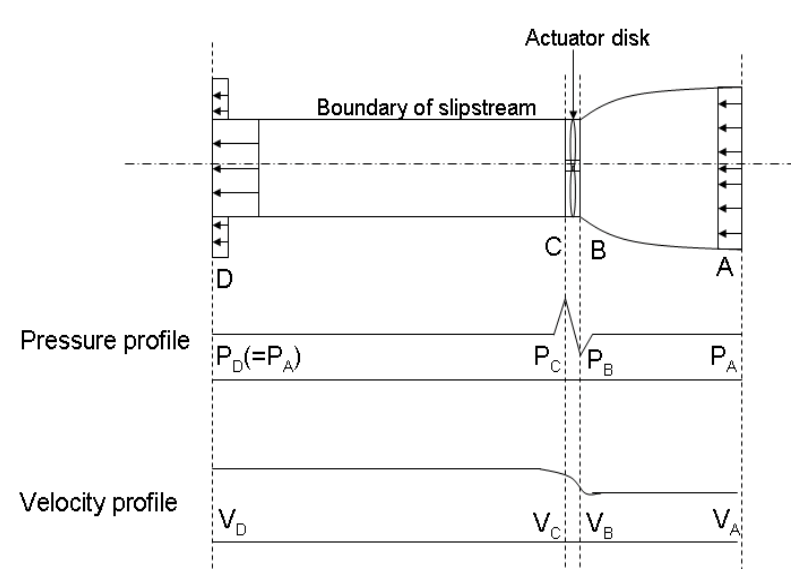

Figure 1: Axial momentum theory (Lam et al 2011) [6].

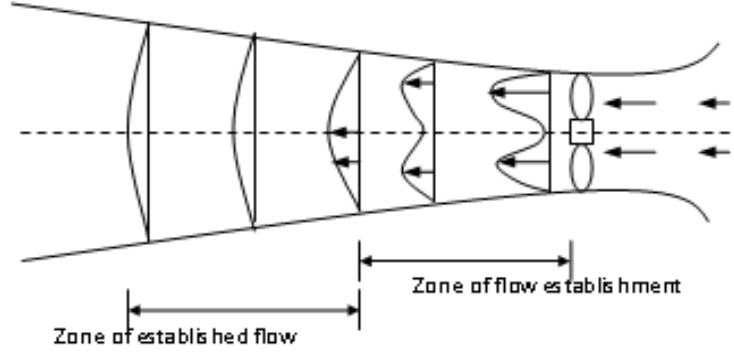

Figure 2: A submerged propeller jet suggested by Hamill et al. [7].

where $\mathrm{n}$ is number of rev per sec of propeller, $\mathrm{D}_{\mathrm{h}}$ is hub diameter, $\mathrm{C}_{\mathrm{t}}$ is thrust coefficient, $\mathrm{D}$ is propeller diameter, $\mathrm{BAR}$ is blade area ratio.

Zone of flow establishment: The zone of flow establishment is the region where the jet was divided into two parts by the influence of the rotating hub. The velocity profiles of this zone contain two symmetric peaked ridges propagating downstream jet.

Predicting maximum velocity of a traverse profile is the first step to understand the whole distribution. This maximum velocity at the zone of flow establishment can be predicted using.

$$
\frac{\mathrm{V}_{\max }}{\mathrm{V}_{0}}=0.87\left(\frac{\mathrm{x}}{\mathrm{D}}\right)^{-(\mathrm{BAR} / 4)}
$$

For the efflux plane and the region up to $0.5 \mathrm{D}$ from the propeller, the distribution of axial velocity can be determine by

$$
\frac{\mathrm{V}_{\mathrm{x}, \mathrm{r}}}{\mathrm{V}}=\mathrm{e}^{\left[-(1 / 2)\left(\left(\mathrm{r}-\mathrm{R}_{\mathrm{mo}}\right) /\left(\mathrm{R}_{\mathrm{mc}}\right.\right.\right.}
$$

and within the zone of flow establishment,

$$
\frac{\mathrm{V}_{\mathrm{x}, \mathrm{r}}}{\mathrm{V}_{\max }}=\mathrm{e}^{\left.\left[-(1 / 2)\left(\left(\mathrm{r}-\mathrm{R}_{\mathrm{mo}}\right) /\left(\mathrm{R}_{\mathrm{mo}} / 2\right)+0.075(\mathrm{X}-\mathrm{R})\right)\right)^{2}\right]}
$$

Where $R_{m o}$ can be obtained using Berger's equation

$$
\mathrm{R}_{\mathrm{mo}}=0.67\left(\mathrm{R}-\mathrm{R}_{\mathrm{h}}\right)
$$

where $R$ is the radius of the propeller and $R_{h}$ is the radius of the propeller hub.

Zone of established flow: The fluid from the two peaked ridges will penetrated into the central axis to produce an individual peaked ridge. This zone has been called zone of established flow. The flow velocity will decelerate along the jet with distance from face. The maximum velocity of this zone can be predicted using the Hashmi's equation

$$
\frac{\mathrm{V}_{\max }}{\mathrm{V}_{0}}=0.638 \mathrm{e}^{(-0.097(\mathrm{x} / \mathrm{D}))}
$$

While the distribution can be calculated using Fuehrer and Romisch's equation

$$
\frac{\mathrm{V}_{\mathrm{x}, \mathrm{r}}}{\mathrm{V}_{\max }}=\mathrm{e}^{\left[-22.2(\mathrm{r} / \mathrm{X})^{2}\right]}
$$

Data collection and analysis: The data obtained for propeller performance from JavaProp software was transfer to Microsoft Excel. Then the data used for this study was selected and form in a new table for further analysis. The propeller performance was determined from data of power, torque, thrust and efficiency obtained. The data calculated for the propeller jet by using the equation was transfer to Microsoft Excel. The analysis for propeller jet included the efflux velocity and the distribution of axial velocity for Zone of Flow Establishment and Zone of Establish Flow.

\section{Result and Discussion}

\section{Propeller performance}

The propeller from UMT RV Discovery vessel was used in this research. The data uses for this research are shown in Table 1.

From the specification of engine and propeller, the propeller performance was analyzed by using JavaProp software. All the data were analyzed using off design analysis for full advance coefficient range. The performance data were shown in Table 2.

From the Figure 3, the graph of propeller performance, both coefficient of thrust and power decrease when the number of advance coefficient increase. The advance coefficient represents the speed of propeller. While the efficiency of the propeller, in the beginning of the advance coefficient from zero to 0.7 the graph gradually increases to the highest point which is 0.58 . Then the efficiency start decrease as advance coefficient increase until the last point. Based on this graph, the propeller is designed with a good performance.

From the Figure 4, power versus propeller speed curve, it is observed that when the propeller speed at zero the power are higher

\begin{tabular}{|c|c|}
\hline Specification & Dimension \\
\hline Propeller diameter & $1.56 \mathrm{~m}$ \\
\hline Hub diameter & $0.21 \mathrm{~m}$ \\
\hline Number of blades & 4 \\
\hline Blade area ratio & 0.7 \\
\hline Propeller RPM & 446.65 \\
\hline Gear box ratio & $4.03: 1$ \\
\hline Engine power & $850 \mathrm{HP}$ \\
\hline Engine RPM & 1800 \\
\hline Max speed & $12 \mathrm{knots}$ \\
\hline
\end{tabular}

Table 1: Engine and propeller specification. 
Citation: Oladokun SO (2015) Study of Efficiency and Environmental Performance of Propeller. J Coast Zone Manag 18: 400. doi: 10.4172/24733350.1000400

Page 3 of 6

\begin{tabular}{|c|c|c|c|c|c|c|c|c|c|}
\hline$v /(n D)$ & $v /(\Omega R)$ & $\mathrm{Ct}$ & $C p$ & $\eta$ & $\begin{array}{c}v \\
{[\mathrm{~m} / \mathrm{s}]}\end{array}$ & $\begin{array}{c}n \\
{[1 / \mathrm{min}]}\end{array}$ & $\begin{array}{l}\text { Power } \\
\text { [MW] }\end{array}$ & $\begin{array}{c}\text { Thrust } \\
{[\mathrm{kN}]}\end{array}$ & $\begin{array}{l}\text { Torque } \\
\text { [kNm] }\end{array}$ \\
\hline 0 & 0 & 0.4145 & 0.3906 & 0.00 & 0 & 447 & 1.53 & 139.68 & 32.67 \\
\hline 0.1 & 0.032 & 0.4179 & 0.3499 & 0.11 & 1.16 & 447 & 1.37 & 140.82 & 29.27 \\
\hline 0.2 & 0.064 & 0.3592 & 0.3308 & 0.21 & 2.32 & 447 & 1.3 & 121.05 & 27.68 \\
\hline 0.3 & 0.095 & 0.3220 & 0.3082 & 0.31 & 3.49 & 447 & 1.21 & 108.52 & 25.78 \\
\hline 0.4 & 0.127 & 0.2823 & 0.2817 & 0.4 & 4.65 & 447 & 1.1 & 95.11 & 23.56 \\
\hline 0.5 & 0.159 & 0.2387 & 0.2501 & 0.48 & 5.81 & 447 & 0.98 & 80.43 & 20.92 \\
\hline 0.6 & 0.191 & 0.1953 & 0.2162 & 0.54 & 6.97 & 447 & 0.85 & 65.82 & 18.09 \\
\hline 0.7 & 0.223 & 0.1418 & 0.1718 & 0.58 & 8.14 & 447 & 0.67 & 47.78 & 14.37 \\
\hline 0.8 & 0.255 & 0.0832 & 0.1204 & 0.55 & 9.30 & 447 & 0.47 & 28.05 & 10.07 \\
\hline 0.9 & 0.286 & 0.0263 & 0.0681 & 0.35 & 10.46 & 447 & 0.27 & 8.87 & 5.70 \\
\hline
\end{tabular}

Table 2: Data of the propeller performance.

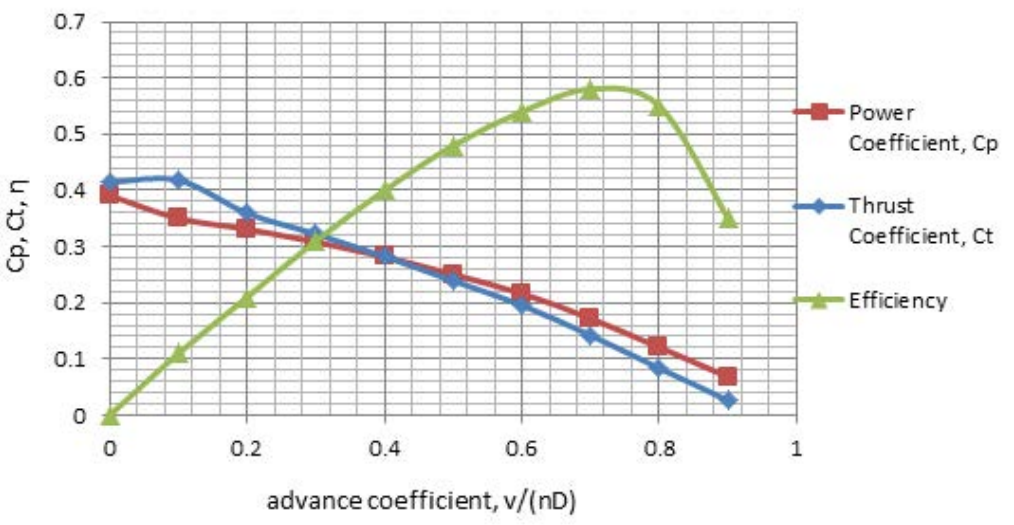

Figure 3: Graph propeller performance.

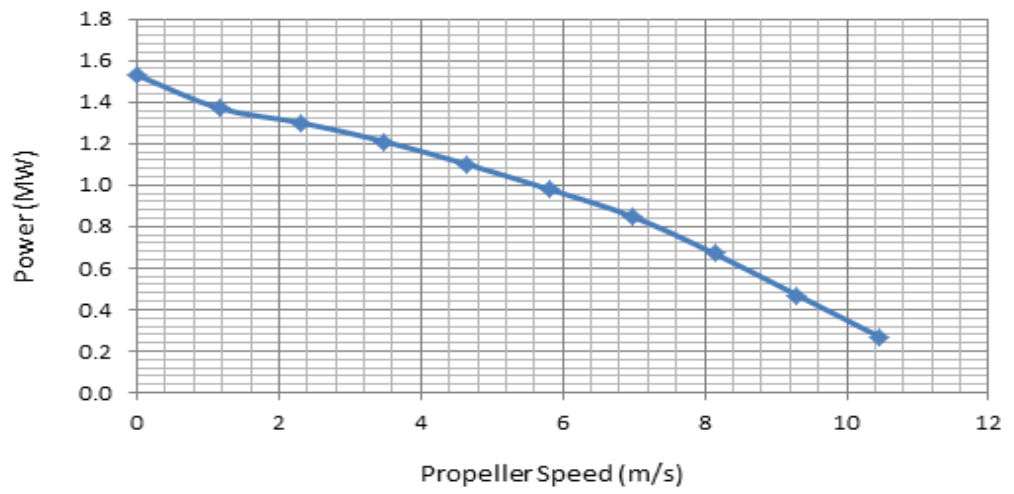

Figure 4: Graph power vesus propeller speed.

which is $1.53 \mathrm{MW}$. From there the power gradually decrease until 0.27 MW as the propeller speed increase to $10.46 \mathrm{~m} / \mathrm{s}$ due to less resistant. Based on the graph the power delivered to the propeller was good.

From the Figure 5, the graph thrust versus propeller speed, its show that when the propeller sDelft Hydraulics speed at $0 \mathrm{~m} / \mathrm{s}$ the thrust produced was $139 \mathrm{kN}$. The thrust value continuous to decrease as the propeller speed increasing. Based on the graph, the thrust produced by the propeller was good. This is because the thrust required are higher when the propeller starts to rotate to drive the ship.

From the Figure 6, the graph torque versus propeller speed, it clearly shows that the torque is inversely as propeller speed. The torque more needed when the propeller speed at $0 \mathrm{~m} / \mathrm{s}$ compare to the speed $10.46 \mathrm{~m} / \mathrm{s}$. Based on the graph, the torque delivered to the propeller was good. This is because the torque was high in the beginning to overcome the resistance to rotate the propeller [11].

\section{Impact of propeller jet}

The propeller jet had been determined by their velocities from the propeller face. For this calculation the propeller specification of RV Discovery used are shown in Table 3. 


\section{Efflux velocity}

The exit plane of a propeller flow is called the efflux velocity. The efflux velocity were calculate using equation (1) which proposed by Hamilet al. While the coefficient can be calculate using equation (2) proposed by Hashmi 1993. From both equations the efflux velocity is $28.05 \mathrm{~m} / \mathrm{s}$. Based on the propeller size, the efflux velocity produced is quiet high.

\section{Zone of flow establishment}

First of all, the maximun velocity at zone of flow establishment should be determined. This maximum velocity was calculated by using equation (3) which is $19.89 \mathrm{~m} / \mathrm{s}$. The axial velocity distribution at zone of flow establishment are divided by two region which is efflux plane at up to $0.5 \mathrm{D}$ and zone of flow establishment $3.25 \mathrm{D}$ for further region in the zone of flow establishment. Equation (4), (5) and (6) were used in this calculation. All the calculated data for this zone are shown in Tables 4 and 5.

Figure 7, it shows the distribution of axial velocity at efflux plane along a radial distance from propeller axis at the distance $0.78 \mathrm{~m}$ from propeller face.The hub didn't produced the axial velocity which describe why the axial velocity is lower at distance $0 \mathrm{~m}$ compare to $0.2 \mathrm{~m}$. Based on the graph, the distribution of axial velocity was good but the axial velocity are high.

Figure 8, shows the distribution of axial velocity at zone of flow establishment along a radial distance from propeller axis at the distance
$5 \mathrm{~m}$ from propeller face. The axial velocity contiuosly decrease until $0.24 \mathrm{~m} / \mathrm{s}$ at distance $3.2 \mathrm{~m}$. Based on the graph, the distribution of axial velocity at this region was not good and the axial velocity are high.

\section{Zone of established flow}

This zone has been called zone of established flow. The flow velocity will decelerate along the jet with distance from face. Equation (7) and (8) were used in this calculation. All the calculated data for this zone are shown in Table 6.

From Figure 9, it is obserevd that the distributions of axial velocity at zone of establish flow along a radial distance from propeller axis at the distance $12 \mathrm{~m}$ from propeller face. Then, the axial velocity reached its lower velocity which is $0.67 \mathrm{~m} / \mathrm{s}$ at distance $4.0 \mathrm{~m}$. Based on the graph, the distribution of axial velocity is not good and the axial velocity are high for this region.

From Figure 10, its clearly shown that the distribution of axial velocity along radial distance from different distance from propeller face. At radial distance of $0 \mathrm{~m}$ the axial velocity increase from $2.69 \mathrm{~m} / \mathrm{s}$ to $10.04 \mathrm{~m} / \mathrm{s}$ and then decrease to $8.48 \mathrm{~m} / \mathrm{s}$.It shows the distribution along radial distance increase as the distance from propeller face increase. Based on the graph, the distribution of axial velocity was good but the axial velocities are high.

In conclusion, this study determines the efficiency and its environmental performance for propeller from UMT RV Discovery. Based on the result of the study, it shows that propeller efficiency depends on the

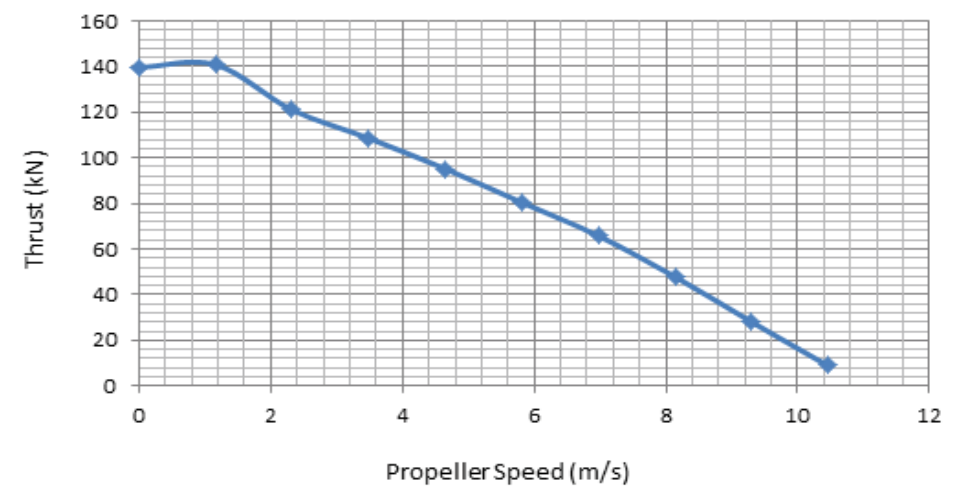

Figure 5: Graph thrust versus propeller speed.

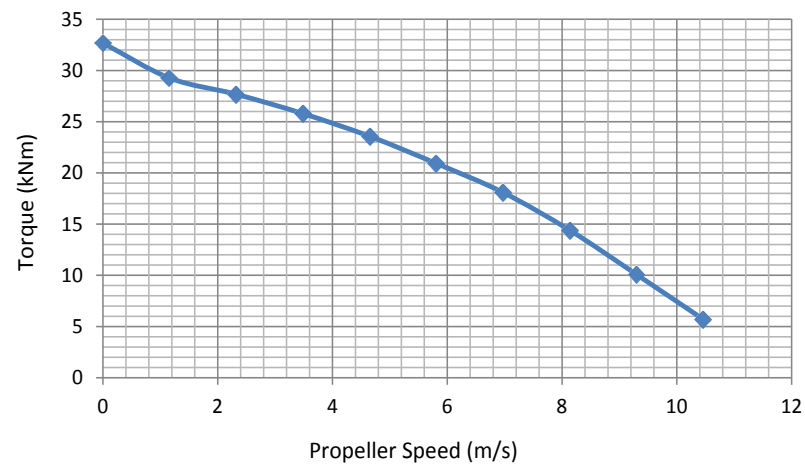

Figure 6: Graph torque versus propeller speed. 
Citation: Oladokun SO (2015) Study of Efficiency and Environmental Performance of Propeller. J Coast Zone Manag 18: 400. doi: 10.4172/24733350.1000400

Page 5 of 6

\begin{tabular}{|c|c|}
\hline Specification & Dimension \\
\hline Propeller diameter, Dp & $1.56 \mathrm{~m}$ \\
\hline Hub diameter, Dh & $0.21 \mathrm{~m}$ \\
\hline Thrust coefficient, $\mathrm{Ct}$ & 0.224 \\
\hline Blade area ratio, BAR & 0.7 \\
\hline Rotation speed & $7.45 \mathrm{rps}$ \\
\hline
\end{tabular}

Table 3: Propeller Specification details.

\begin{tabular}{|c|c|c|c|c|}
\hline $\mathbf{V m a x}(\mathbf{m} / \mathbf{s})$ & $\mathbf{R m o}(\mathbf{m} / \mathbf{s})$ & $\mathbf{x}(\mathbf{m})$ & $\mathbf{r}(\mathbf{m})$ & $\mathbf{V x ,} \mathbf{r}(\mathbf{m} / \mathbf{s})$ \\
\hline 19.89 & 0.9 & 0.78 & 0.0 & 2.69 \\
\hline 19.89 & 0.9 & 0.78 & 0.2 & 5.93 \\
\hline 19.89 & 0.9 & 0.78 & 0.4 & 10.72 \\
\hline 19.89 & 0.9 & 0.78 & 0.6 & 15.91 \\
\hline 19.89 & 0.9 & 0.78 & 0.8 & 19.41 \\
\hline 19.89 & 0.9 & 0.78 & 1.0 & 19.41 \\
\hline 19.89 & 0.9 & 0.78 & 1.2 & 15.91 \\
\hline 19.89 & 0.9 & 0.78 & 1.4 & 10.71 \\
\hline 19.89 & 0.9 & 0.78 & 1.6 & 5.93 \\
\hline 19.89 & 0.9 & 0.78 & 1.8 & 2.69 \\
\hline 19.89 & 0.9 & 0.78 & 2.0 & 0.99 \\
\hline
\end{tabular}

Table 4: Data of axial velocity distribution at efflux plane (0.5D).

\begin{tabular}{|c|c|c|c|c|}
\hline $\mathbf{V m a x}(\mathbf{m} / \mathbf{s})$ & $\mathbf{R m o}(\mathbf{m})$ & $\mathbf{x}(\mathbf{m})$ & $\mathbf{r}(\mathbf{m})$ & $\mathbf{V x ,} \mathbf{r}(\mathbf{m} / \mathbf{s})$ \\
\hline 19.89 & 0.9 & 5 & 0.0 & 10.04 \\
\hline 19.89 & 0.9 & 5 & 0.4 & 16.11 \\
\hline 19.89 & 0.9 & 5 & 0.8 & 19.73 \\
\hline 19.89 & 0.9 & 5 & 1.2 & 18.43 \\
\hline 19.89 & 0.9 & 5 & 1.6 & 13.18 \\
\hline 19.89 & 0.9 & 5 & 2.0 & 7.16 \\
\hline 19.89 & 0.9 & 5 & 2.4 & 2.98 \\
\hline 19.89 & 0.9 & 5 & 2.8 & 0.95 \\
\hline 19.89 & 0.9 & 5 & 3.2 & 0.24 \\
\hline
\end{tabular}

Table 5: Data of axial velocity distribution at zone of flow establishment (3.25D).

\begin{tabular}{|c|c|c|c|}
\hline $\mathbf{V m a x}(\mathbf{m} / \mathbf{s})$ & $\mathbf{x}(\mathbf{m})$ & $\mathbf{r}(\mathbf{m})$ & $\mathbf{V x ,} \mathbf{r}(\mathbf{m} / \mathbf{s})$ \\
\hline 8.48 & 12 & 0.0 & 8.48 \\
\hline 8.48 & 12 & 0.4 & 8.28 \\
\hline 8.48 & 12 & 0.8 & 7.72 \\
\hline 8.48 & 12 & 1.2 & 6.78 \\
\hline 8.48 & 12 & 1.6 & 5.68 \\
\hline 8.48 & 12 & 2.0 & 4.58 \\
\hline 8.48 & 12 & 2.4 & 3.48 \\
\hline 8.48 & 12 & 2.8 & 2.54 \\
\hline 8.48 & 12 & 3.2 & 1.78 \\
\hline 8.48 & 12 & 3.6 & 1.18 \\
\hline 8.48 & 12 & 4.0 & 0.67 \\
\hline
\end{tabular}

Table 6: Calculate data for zone of establish flow.

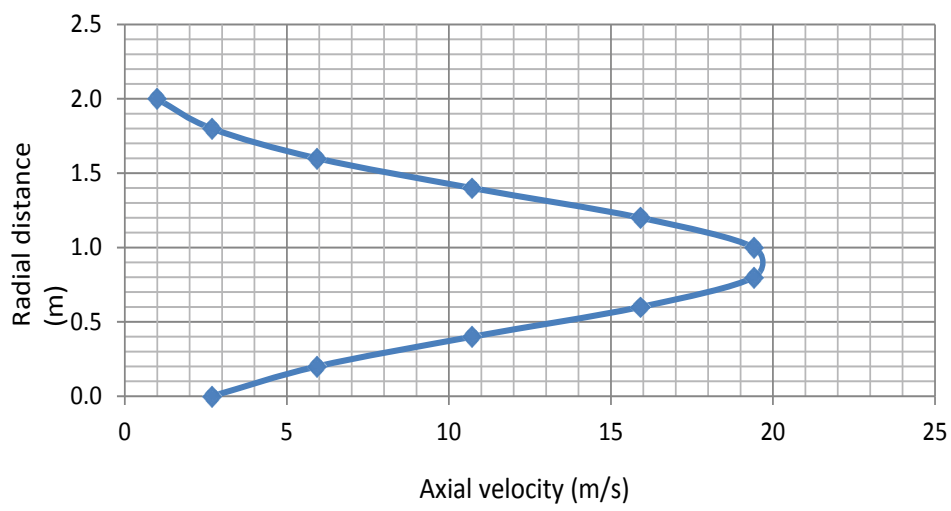

Figure 7: Distribution of axial velocity at efflux plane (0.5D)

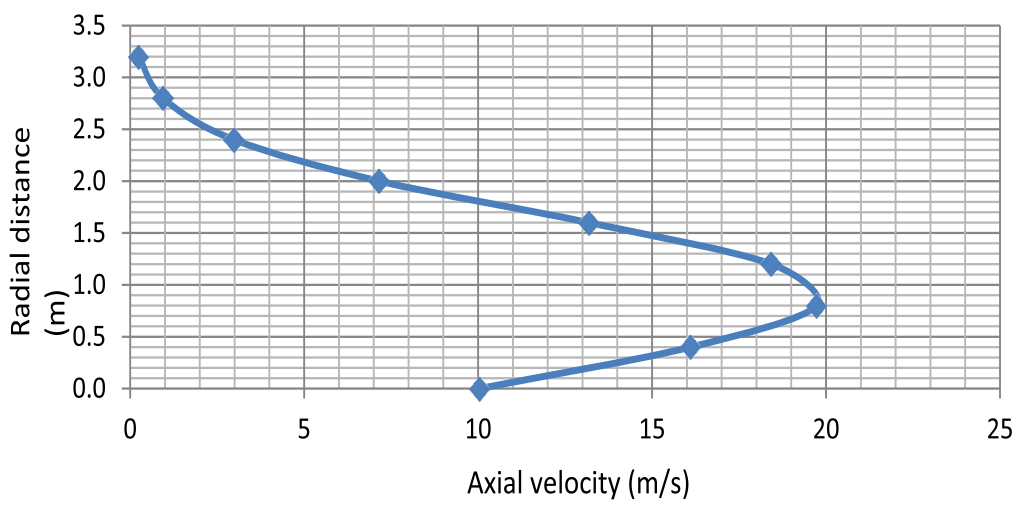

Figure 8: Distribution of axial velocity at zone of flow establishment (3.25D) 
Citation: Oladokun SO (2015) Study of Efficiency and Environmental Performance of Propeller. J Coast Zone Manag 18: 400. doi: 10.4172/24733350.1000400

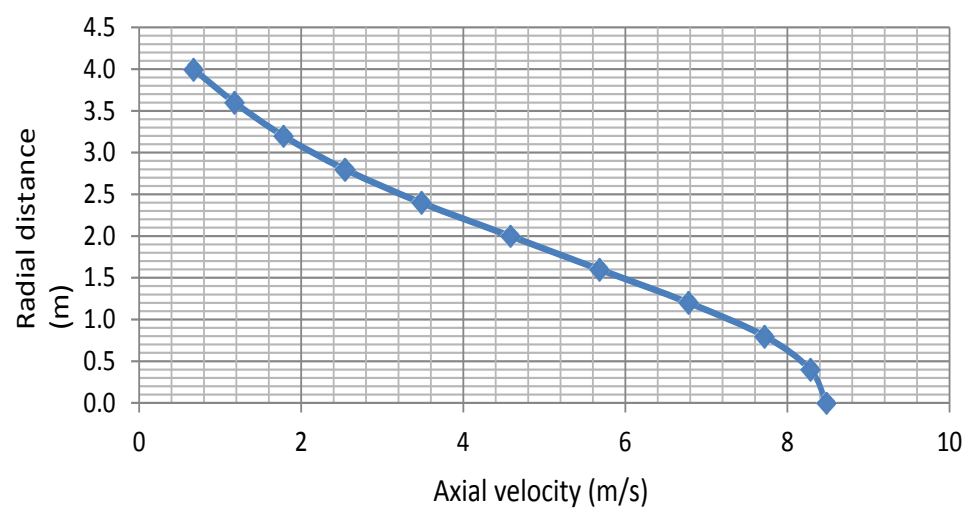

Figure 9: Distribution of axial velocity at zone of establish flow (8D)

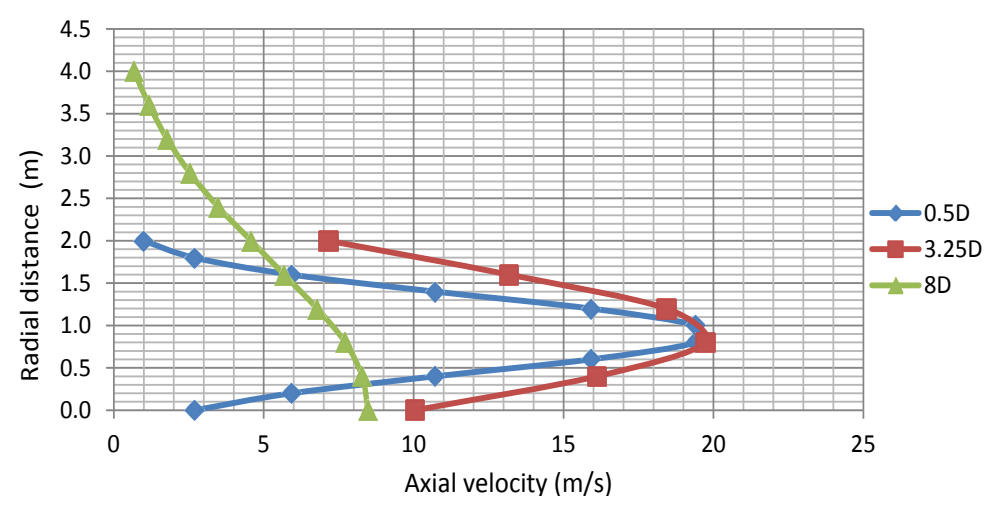

Figure 10: Distribution of axial velocity at $0.5 \mathrm{D}, 3.25 \mathrm{D}$ and $8 \mathrm{D}$ from propeller face.

relation between rate of revolution of propeller and power delivered to the propeller. The result of axial velocity and its distribution was along the radial distance from propeller axis for a certain distance from propeller face. The study also shows that the axial velocity are higher at zone of flow establishment compare to the zone of establish flow. This is because at zone of flow establishment there are turbulence flow while at zone of establish flow the turbulence flow has expanded and establish due to the distance from propeller face.

\section{Recommendation for the future research are:}

i. More than one propeller with different specification to make good comparison and to get a better result is suggested.

ii. Use computational fluid dynamic (CFD) simulation software to analysis the parameter involved for an accurate result. Besides that it's also a faster and cheaper method.

iii. Further study also needs to consider the hull interaction which generates the ship wake wave.

\section{Acknowledgement}

The author aknowldge the direct contribution of Syafic in this work.

\section{References}

1. Bergh H, Cederwall K (1981) Propeller Erosion in Harbours, Bulletin No. TRITAVBI-107. Hydraulics Laboratory, Royal Institute of Technology, Stockholm, Sweden.
2. Blaauw HG, Kaa EJ, Van de (1978) Erosion of Bottom and Sloping Banks Caused by the Screw Race of Manoeuvring Ships. Delft Hydraulics Laboratory, Netherlands 202

3. Brewster PM (1997) Modelling the wash from a ship's propeller, Thesis submitted to the Queen's University of Belfast for the degree of Doctor of Philosophy.

4. Stumbo S, Fox K, Dvorak F, Elliot L (1999) The Prediction, Measurement, and Analysis of Wake Wash from Marine Vessels, Marine Tech. 36: 248 -260.

5. Gaffary MM (2009) Computerized Method for Propeller Design of Optimum Diameter and RPM, Intl Maritime Assoc of Mediterranean.

6. Lam W, Hamil GA, Song YC, Robinson DJ, Raghunathan S (2011) A Review of The Equations Used to Predict the Velocity Distribution within a Ship's Propeller Jet. Ocean Engineering 38: 1-10

7. Lam W, Hamil GA, Robinson DJ, Raghunathan S, Kee C (2006) Simulations of a Ship's Propeller Wash, International Offshore and Polar Engineering Conference 1098-6189.

8. Parnell KE, Mcdonald SC, Burke AE (2007) Shoreline effects of vessel wakes, Marlborough Sounds, New Zealand. Journal of Coastal Research 50: 502 - 506.

9. Qurrain R (1994) Influence of the sea bed geometry and berth geometry on the hydrodynamics of the wash from a ships propeller. The Queen's University of Belfast, Northern Ireland

10. Wolter C, Arlinghaus R, Sukhodolov A, Engelhardt C (2004) Model of Navigation-Induced Currents in Inland Waterways and Implications for Juvenile Fish Displacement. Environmental Management 34: 656-668.

11. Harvald SVAA (1983) Resistance and Propulsion of Ships. 